\title{
Detection of genetic variation between and within populations of Gliricidia sepium and G. maculata using RAPD markers
}

\author{
K. J. CHALMERS, R. WAUGH, J. I. SPRENT,* A. J. SIMONS $\uparrow \&$ W. POWELL $\ddagger$ \\ Scottish Crop Research Institute, Invergowrie, Dundee, ${ }^{*}$ Department of Biological Sciences, University of Dundee, \\ Dundee, Scotland and tOxford Forestry Institute, Department of Plant Sciences, University of Oxford, Parks Road, \\ Oxford, England
}

\begin{abstract}
Gliricidia sepium and G. maculata are multi-purpose leguminous trees native to Central America and Mexico. Research programmes have been initiated to define the native distribution of Gliricidia and sample the spectrum of genetic variation. To date, there has been little systematic assessment of genetic variability in multi-purpose tree species. Accurate estimates of diversity between- and within-populations are considered a prerequisite for the optimization of sampling and breeding strategies. We have used a PCR-based polymorphic assay procedure (RAPDs) to monitor genetic variability in Gliricidia. Extensive genetic variability was detected between species and the variability was partitioned into between- and within-population components. On average, most (60 per cent) of the variation occurs between $G$. sepium populations but oligonucleotide primers differed in their capacity to detect variability between and within populations. Population-specific genetic markers were identified. RAPDs provide a cost-effective method for the precise and routine evaluation of variability and may be used to identify areas of maximum diversity. The approaches outlined have general applicability to a range of organisms and are discussed in relation to the exploitation of multi-purpose tree species of the tropics.
\end{abstract}

Keywords: genetics, Gliricidia, population, RAPDs, woody perennials.

\section{Introduction}

Multi-purpose tree species have recently received increased attention because they could enhance the productivity, diversity and sustainability of marginal ecosystems. Despite their ecological and agricultural importance, however, little is known of the basic biology of non-industrial trees (Simons, 1991). The genetic improvement of any organism depends on the existence, nature and extent of the genetic variability available for manipulation. The partitioning of variability between and within populations will influence the breeding strategy to be adopted. There has been little systematic assessment of genetic variability or evaluation of the spatial distribution of diversity within the gene pools of multi-purpose tree species.

Traditionally, genetic resources have been characterized by a combination of morphological and agronomic traits. The effectiveness of this approach to estimate genetic diversity, however, has been questioned by several authors (Gottlieb, 1977; Brown, 1979). As an alternative, isozymes have been used extensively to monitor diversity (Soltis \& Soltis, 1990) and optimize breeding strategies for tree species (Yeh, 1989). Numerous studies have revealed the nonrandom distribution of genetic variation and emphasized the importance of understanding the genetic structure of a population (Loveless \& Hamrick, 1984). Recent reviews of the levels of variation detected in a range of plant species, based on isozyme data, reveal that tropical tree species maintain most of their variation within populations (Hamrick, 1990). This suggests that the classical forestry approach, which considers provenance or geographical variation as an accurate predictor of the diversity spectrum within a species, may be inappropriate. The extreme disturbance of the natural gene pools of many multi-purpose tropical tree species, through human intervention, also indicates that the partitioning and distribution of variability may be complex. These factors emphasize that there is an urgent need to examine the population genetic structure of multi-purpose tree species. 
Molecular and biochemical techniques provide a powerful set of tools for the study of plant population genetics. Numerous studies have used restriction-site diversity to infer population genetic structure (Clegg, 1989a,b). Restriction fragment length polymorphisms (RFLP) are the most frequently used type of DNA marker. The RFLP assay requires large quantities of relatively pure DNA, species-specific DNA probes, and generally uses short-lived radio-isotopes in the detection system. Furthermore, RFLP analysis is laborious, making it impractical for many population-based studies.

The analysis of nucleotide sequence variability has been revolutionized by the development of the polymerase chain reaction (PCR) (Saiki et al., 1988). A major limitation of the procedure, however, has been the requirement for DNA-sequence information (Innis et al., 1990). Recently, Williams et al. (1990) and Welsh \& McClelland (1990) described a novel procedure for the identification of polymorphism in plants based on PCR which is not dependent on having prior knowledge of a DNA sequence. Randomly amplified polymorphic DNA sequences or RAPD markers are based on the amplificatoin of unknown DNA sequences using single, short, random oligonucleotide primers. The RAPD method overcomes many of the technical limitations of RFLPs and has been used for genetic fingerprinting (Wilde et al., 1992), creating linkage maps (Rafalski et al., 1991), locating disease resistance genes (Martin et al., 1991; Michelmore et al., 1992), identifying chromosome-specific markers (Quiros et al., 1991) and characterization of somatic hybrids (Baird et al., 1992).

Most studies of diversity and population structure of tree species have concentrated on commercial species, primarily temperate zone conifers. In this paper, we report the use of RAPD markers to investigate the extent and distribution of genetic diversity in Gliricidia sepium and $G$. maculata. These are nitrogen-fixing trees native to Central America and Mexico (Hughes, 1987), but are important components of many agroforestry systems in the topics. G. sepium is an aggressive colonizing species often forming dense pure stands. It is entomophilous and an obligate out-breeder (A. J. Simons, unpublished observations). A systematic evaluation and quantification of the variability available in the Gliricidia gene pool will make it easier to exploit this species as a multi-purpose tree for tropical agroforestry.

\section{Materials and methods}

\section{Plant material}

The species and populations studied together with their geographical origin are given in Table 1.

\section{DNA extractions}

DNA was isolated from fresh leaf material using a modification of the method described by Edwards et al. (1991). Samples were collected using the lid of a sterile Eppendorf tube to pinch out a disc of leaf material. This ensured a uniform sample size and reduced the possibility of contamination arising from handling the tissue. The tissue was macerated in the original tube at room temperature using disposable Eppendorf grinders, with the addition of 10-20 mg of Polyclar AT (polyvinylpyrrolidone, insoluble). Fourhundred microlitres of extraction buffer (200 mM Tris $\mathrm{HCl}, \mathrm{pH} 7.0,250 \mathrm{~mm} \mathrm{NaCl}, 25 \mathrm{~mm}$ EDTA, 0.5 per cent SDS, $10 \mathrm{~mm}$ mercaptoethanol) were added and the sample vortexed for $5 \mathrm{~s}$. The extracts were centrifuged at 13,000 r.p.m. for $1 \mathrm{~min}$ and the supernatant transferred to a clean tube. The supernatant was extracted with phenol/chloroform, then chloroform

Table 1 Gliricidia sepium and G. maculata samples studied

\begin{tabular}{lllll}
\hline Sample number & Species & Indent number & Origin & \\
\hline $1-5$ & G. maculata & $42 / 85$ & Mexico & Quintana \\
$6-10$ & G. maculata & $43 / 87$ & Mexico & Xeb \\
$11-15$ & G. sepium & $72 / 87$ & Thailand & Chumphon \\
$16-20$ & G. sepium & $40 / 85$ & Mexico & Arriaga \\
$21-25$ & G. sepium & $59 / 87$ & Guatemala & Vado Hondo \\
$26-30$ & G. sepium & $1 / 86$ & Venezuela & Mariara \\
$31-35$ & G. sepium & $13 / 86$ & Panama & Pedasi \\
$36-40$ & G. sepium & $11 / 86$ & Costa Rica & El Roblar \\
$41-45$ & G. sepium & $12 / 86$ & Costa Rica & Playa Tamarindo \\
$46-50$ & G. sepium & $31 / 84$ & Nicaragua & Managua \\
\hline
\end{tabular}


and the resulting aqueous fraction were mixed with $300 \mu \mathrm{l}$ isopropanol and left at room temperature for 2 min to precipitate the DNA. Following centrifugation at 13,000 r.p.m. for $5 \mathrm{~min}$, the DNA pellet was vacuum dried and dissolved in $100 \mu \mathrm{l}$ TE buffer $(10 \mathrm{~mm}$ Tris $\mathrm{HCl}, \mathrm{pH} 7.5,1 \mathrm{~mm}$ EDTA). The DNA was stable at $4^{\circ} \mathrm{C}$ for at least 12 weeks. Four microlitres of this sample was sufficient for a standard 100- $\mu$ l PCR reaction.

\section{Polymerase chain reaction (PCR)}

PCR reaction mixtures ( $100 \mu \mathrm{l}$ final volume) contained approximately $100 \mathrm{ng}$ genomic DNA, dATP, dCTP, dGTP and dTTP each at $100 \mu \mathrm{M}$ final concentration, $200 \mathrm{~nm}$ primer, $1 \times$ Taq polymerase buffer and 1.3 units of Taq polymerase (Northumbria Biologicals Ltd). Each reaction was overlaid with $100 \mu \mathrm{l}$ of mineral oil to prevent evaporation. The random sequence 10-mer primers used in this study (Table 2) were synthesized on an applied Bio-systems 391 PCRmate oligonucleotide synthesizer. Samples for enzymatic amplification were subjected to 45 repeats of the following thermal cycle: $1 \mathrm{~min}$ at $92^{\circ} \mathrm{C}, 3 \mathrm{~min}$ at $35^{\circ} \mathrm{C}$ and $2 \mathrm{~min}$ at $72^{\circ} \mathrm{C}$. After the final cycle, samples were incubated for a further $3 \mathrm{~min}$ at $72^{\circ} \mathrm{C}$ then held at $4^{\circ} \mathrm{C}$ prior to analysis. Fragments generated by amplification were separated according to size on 2 per cent agarose gels run in $1 \times \mathrm{TBE}$ ( $89 \mathrm{~mm}$ Tris $\mathrm{HCl}$, pH 8.3, $89 \mathrm{~mm}$ Boric acid, $5 \mathrm{~mm}$ EDTA), stained with ethidium bromide and visualized by illumination with ultraviolet light $(312 \mathrm{~mm})$.

\section{Primer and product indexing}

The following conversion was adhered to throughout. Consider, for example, the amplification product designated SC10-60. SC10-60-G900 was generated by

Table 2 Random oligonucleotide primer sequences

\begin{tabular}{ll}
\hline Primer & Sequence \\
\hline SC10-30 & 5'CCGAACGGGT \\
SC10-34 $10-35$ & 5'GGTGGGTGCT \\
SC10-3 & 5'GTGCGGACAG \\
SC10-36 & 5'TCACCGAACG \\
SC10-37 & 5'GCCAATCCTG \\
SC10-39 & 5'GGACGGGTGC \\
SC10-45 & 5'GGACCACCAT \\
SC10-49 $10-58$ & 5'CCACGACGAT \\
SC10-59 & 5'CGGGAGACCC \\
SC10-59 $10-60$ & 5'GCATGGAGCT \\
SC10 & 5'GGCCTTGAGT \\
\hline
\end{tabular}

primer SC10-60 and was synthesized at the Scottish Crop Research Institute, it is $10 \mathrm{nt}$ in length and it is number 60 in our primer collection. The product of interest, G900, generated with this primer, is from Gliricidia and is $900 \mathrm{nt}$ in length.

\section{Hybridization analysis}

Amplified DNA fragments separated according to their length by polyacrylamide gel electrophoresis were transferred electrophoretically to Biodyne Nylon membrane (PALL) in a Biorad electroblotting apparatus in $0.4 \mathrm{M} \mathrm{TBE}$ at $1.5 \mathrm{~A}$ constant current for $1 \mathrm{~h}$. Fragments to be used as probes were excised and the DNA recovered from the gel by electroelution in dialysis tubing as described by Maniatis et al. (1982). Isolated fragments were labelled by random priming (Feinberg \& Vogelstein, 1984) with ${ }^{32} \mathrm{P}$ dCTP $(3,000$ $\mathrm{Ci} \mathrm{mmol}{ }^{-1}$, ICN Biomedicals), and used to probe the prepared blots of standard procedures (Maniatis et al., 1982). After hybridization, the blots were washed in several changes of $0.1 \times \mathrm{SSC}, 0.1$ per cent $\mathrm{SDS}$ at $65^{\circ} \mathrm{C}$ and the hybridizing fragments revealed by autoradiography.

\section{Results}

The DNA mini-preparation extraction procedure, using a single-leaf disc, produced DNA of sufficient quality for 25 PCR reactions using the 10-mer oligonucleotides listed in Table 2. Ten of the 11 primers evaluated generated amplification products of varying sizes which detected polymorphism between Gliricidia genotypes. An example of the polymorphism detected with SC10-60 is given in Fig. 1, which clearly discriminates between $G$. sepium and G. maculata. In addition, molecular variability is detected between and within the $G$. sepium populations. Samples $21-25$, originating from Guatemala, and samples 16-20, from Mexico, are clearly polymorphic for a major $0.9 \mathrm{~kb}$ amplification product generated by SC10-60 (designated SC1060-G900). Amplification products, which are unique to the G. sepium samples from Thailand, were also identified with SC10-38 (Fig. 2). The Panamanian and Venezuelan populations exhibited relatively low levels of variability, by contrast with the polymorphism detected in the remaining populations (Fig. 3).

\section{Partitioning of genetic variability between and within G. sepium populations}

The number of polymorphic loci detected with the nine primers for the eight $G$. sepium populations is given in Table 3. The total number of polymorphic loci 


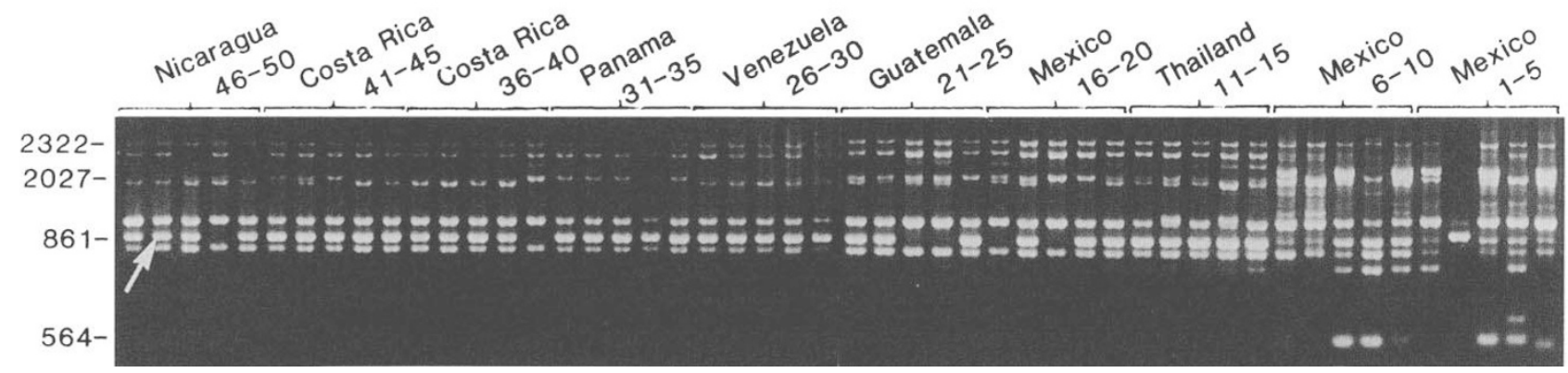

Fig. 1 Amplification products generated from five individuals of 10 populations of Gliricidia spp. using primer SC10-60. The products were generated and resolved as described in the Materials and Methods. The polymorphic 900 bp fragment (SC10-60G900) is highlighted (arrow).

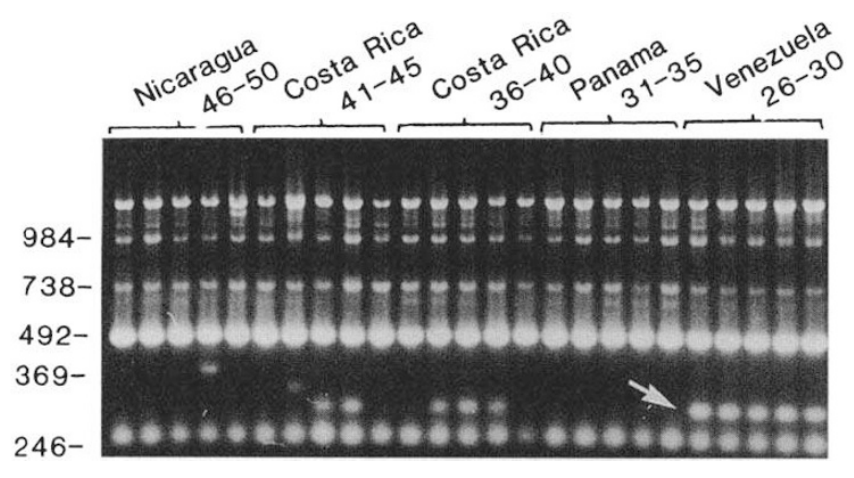

Fig. 2 Monomorphism in the Panamanian (tracks 31-35) and Venezuelan (tracks 26-30) populations for the presence or absence of SC10-38-G300 (arrow) are contrasted with the polymorphism within the Costa Rican (tracks 36-40 and 41-45) and Nicaraguan (tracks 46-50) populations.

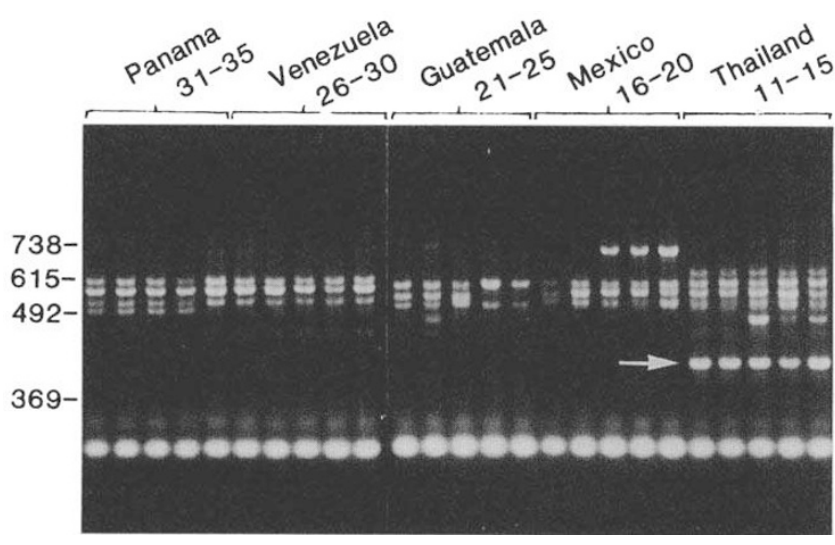

Fig. 3 Products of PCR amplification from five populations with SC10-58. The presence of SC10-58-G420 (arrow) clearly distinguishes the Thailand population from the other populations. detected varied between primers and populations. For example, primer SC10-36 and SC10-59 detected a total of 12 and 11 loci respectively. The Venezuelan and Panamanian populations are characterized by being monomorphic for seven of the nine primers evaluated. The phenotypic frequencies detected with the nine primers evaluated for the eight $G$. sepium populations were calculated and estimates of diversity $\left(H_{0}\right)$ within populations were obtained using Shannon's information measure $H_{0}=-\Sigma p_{\mathrm{i}} \log _{2} p_{\mathrm{i}}$, where $p_{\mathrm{i}}$ is the phenotypic frequency (King \& Schaal, 1989). Estimates of genetic diversity within populations are given for each primer in Table 4. Overall the Venezuelan and Panama populations exhibit relatively low levels of within-population variability. The five individual genotypes assayed were found to be monomorphic for seven primers in the case of the Venezuelan populations and for six of the nine primers in the case of the Panamanian population. The Nicaraguan and Guatemalan populations exhibited the highest levels of within-population variability. Information on those primers which identify unique phenotypes with a particular G. sepium population is also presented in Table 4. For example, SC10-39 identified unique phenotypes with three populations, two of which originate from Venezuela and Panama.

Shannon's index of phenotypic diversity was used to partition the diversity into within- and between-population components (Table 5). $H_{\text {pop }}$ provides a measure of the average diversity within populations. SC10-59 detects the most and SC10-39 the least within-population variability. An examination of the proportion of diversity present within populations $\left(H_{\mathrm{pop}} / H_{\mathrm{sp}}\right)$ and between populations $\left(H_{\mathrm{sp}}-H_{\mathrm{pop}} / H_{\mathrm{sp}}\right)$ indicates that, on average, most of the diversity (60 per cent) occurs between $G$. sepium populations. The distribution of 
Table 3 Polymorphic loci detected with nine primers for eight populations of G. sepium (proportion of polymorphic loci)

\begin{tabular}{|c|c|c|c|c|c|c|c|c|c|}
\hline \multirow[b]{2}{*}{ Primer } & \multicolumn{8}{|c|}{ Location sample number } & \multirow{2}{*}{$\begin{array}{l}\text { Total number } \\
\text { polymorphic } \\
\text { loci }\end{array}$} \\
\hline & $\begin{array}{l}\text { Thailand } \\
11-15\end{array}$ & $\begin{array}{l}\text { Mexico } \\
16-20\end{array}$ & $\begin{array}{l}\text { Guatemala } \\
21-25\end{array}$ & $\begin{array}{l}\text { Venezuela } \\
26-30\end{array}$ & $\begin{array}{l}\text { Panama } \\
31-35\end{array}$ & $\begin{array}{l}\text { Costa Rica } \\
36-40\end{array}$ & $\begin{array}{l}\text { Costa Rica } \\
41-45\end{array}$ & $\begin{array}{l}\text { Nicaragua } \\
46-50\end{array}$ & \\
\hline SC10-30 & $1(0.059)$ & $2(0.118)$ & $1(0.059)$ & $1(0.059)$ & $0(0.000)$ & $1(0.059)$ & $3(0.176)$ & $2(0.118)$ & $6(0.353)$ \\
\hline SC10-34 & $0(0.000)$ & $1(0.250)$ & $1(0.250)$ & $0(0.000)$ & $0(0.000)$ & $3(0.750)$ & $2(0.250)$ & $2(0.250)$ & $7(0.875)$ \\
\hline SC10-36 & $7(0.583)$ & $5(0.417)$ & $4(0.333)$ & $0(0.000)$ & $0(0.000)$ & $0(0.000)$ & $3(0.250)$ & $6(0.500)$ & $12(1.000)$ \\
\hline SC10-39 & $3(0.428)$ & $1(0.125)$ & $2(0.250)$ & $0(0.000)$ & $0(0.000)$ & $0(0.000)$ & $1(0.125)$ & $1(0.125)$ & $7(0.636)$ \\
\hline SC10-45 & $9(0.000)$ & $2(0.500)$ & $2(0.500)$ & $0 .(0.000)$ & $0(0.000)$ & $1(0.250)$ & $1(0.250)$ & $1(0.250)$ & $4(0.219)$ \\
\hline SC10-49 & $1(0.250)$ & $1(0.250)$ & $1(0.250)$ & $0(0.000)$ & $0(0.000)$ & $1(0.250)$ & $1(0.250)$ & $2(0.500)$ & $2(0.500)$ \\
\hline SC10-58 & $1(0.111)$ & $1(0.111)$ & $2(0.222)$ & $0(0.000)$ & $1(0.111)$ & $2(0.222)$ & $3(0.333)$ & $4(0.444)$ & $8(0.889)$ \\
\hline SC10-59 & $4(0.267)$ & $4(0.267)$ & $5(0.333)$ & $2(0.133)$ & $1(0.067)$ & $3(0.200)$ & $7(0.467)$ & $3(0.200)$ & $11(0.733)$ \\
\hline SC $10-60$ & $2(0.222)$ & $3(0.333)$ & $3(0.333)$ & $0(0.000)$ & $0(0.000)$ & $4(0.444)$ & $3(0.333)$ & $3(0.333)$ & $6(0.667)$ \\
\hline
\end{tabular}

Table 4 Estimates of genetic diversity $\left(H_{0}\right)$ within populations for $G$. sepium sampled from eight locations

\begin{tabular}{lllllllll}
\hline \multicolumn{7}{l}{ Location sample number } \\
\cline { 2 - 9 } Primer & $\begin{array}{l}\text { Thailand } \\
11-15\end{array}$ & $\begin{array}{l}\text { Mexico } \\
16-20\end{array}$ & $\begin{array}{l}\text { Guatemala } \\
21-25\end{array}$ & $\begin{array}{l}\text { Venezuela } \\
26-30\end{array}$ & $\begin{array}{l}\text { Panama } \\
31-35\end{array}$ & $\begin{array}{l}\text { Costa Rica } \\
36-40\end{array}$ & $\begin{array}{l}\text { Costa Rica } \\
41-45\end{array}$ & $\begin{array}{l}\text { Nicaragua } \\
46-50\end{array}$ \\
\hline SC10-30 & 0.722 & 1.585 & 0.722 & 0.722 & 0.000 & 0.722 & 1.522 & 1.371 \\
SC10-34 & $0.000^{*}$ & 0.918 & 0.722 & 0.000 & 0.000 & 2.386 & 1.371 & 2.386 \\
SC10-36 & $2.386^{*}$ & $1.585^{*}$ & 2.322 & 0.000 & 1.500 & 1.371 & 1.522 & 2.322 \\
SC10-39 & $0.971^{*}$ & 0.971 & 1.522 & $0.000^{*}$ & $0.000^{*}$ & 0.000 & 0.722 & 0.971 \\
SC10-45 & $0.000^{*}$ & $0.722^{*}$ & 1.371 & 0.000 & 0.000 & 0.971 & 0.971 & 0.722 \\
SC10-49 & 0.811 & 1.000 & 0.722 & 0.000 & 0.000 & 0.971 & 0.971 & 0.722 \\
SC10-58 & $0.971^{*}$ & 0.971 & 1.522 & 0.000 & 0.722 & 1.371 & 1.522 & 0.918 \\
SC10-59 & 2.322 & 2.386 & 2.322 & 0.722 & $1.522^{*}$ & 2.386 & 2.322 & 2.322 \\
SC10-60 & 2.386 & 2.322 & 2.386 & 0.000 & 0.000 & 1.371 & 1.522 & 2.386 \\
$\dot{x}$ & 1.174 & 1.384 & 1.512 & 0.160 & 0.416 & 1.277 & 1.382 & 1.754 \\
\hline
\end{tabular}

*Indicates populations consisting entirely of unique RAPD phenotypes.

Table 5 Partitioning of the genetic diversity between- and within-populations of $G$. sepium for nine random oligonucleotide primers

\begin{tabular}{lllll}
\hline Primer & $H_{\text {pop }}$ & $H_{\text {sp }}$ & $H_{\text {pop }} / H_{\text {sp }}$ & $\left(H_{\text {sp }}-H_{\text {pop }}\right) / H_{\text {sp }}$ \\
\hline SC10-30 & 0.921 & 2.344 & 0.393 & 0.607 \\
SC10-34 & 0.973 & 2.292 & 0.424 & 0.576 \\
SC10-36 & 1.626 & 4.229 & 0.384 & 0.616 \\
SC10-39 & 0.645 & 3.146 & 0.205 & 0.795 \\
SC10-45 & 0.595 & 2.336 & 0.255 & 0.745 \\
SC10-49 & 0.851 & 1.807 & 0.471 & 0.529 \\
SC10-58 & 1.547 & 2.804 & 0.552 & 0.448 \\
SC10-59 & 2.038 & 4.682 & 0.435 & 0.565 \\
SC10-60 & 1.547 & 3.146 & 0.491 & 0.509 \\
$\bar{x}$ & 1.194 & 2.976 & 0.401 & 0.599 \\
\hline
\end{tabular}

variability between and within populations, however, does vary between primers. For example, SC10-39 detects most variability between populations $(80$ per cent) whereas primer 58 detects most variation within populations ( 55 per cent).

To complement the analysis based on phenotypic frequencies Nei's estimate of similarity (Nei, 1972), based on the number of shared amplification products (Nei \& Li, 1979), was used to generate a similarity matrix (Table 6). The populations from Venezuela and Panama exhibit the least variability and the Mexican population exhibits the most. The proportion of shared fragments ranges from 0.50 to 0.81 and the population introduced into Thailand is most similar to the Mexican and Guatemalan populations. The similarity matrix 
Table 6 Similarity matrix generated from Nei \& Li's (1976) estimate of similarity based on the number of shared fragments. The variability within populations is represented by the leading diagonal. The remaining components of the matrix are based on the means of all five individuals for each population

\begin{tabular}{lllllllll}
\hline & Thailand & Mexico & Guatemala & Panama & Venezuela & $\begin{array}{l}\text { Costa Rica } \\
(11 / 86)\end{array}$ & $\begin{array}{l}\text { Costa Rica } \\
(12 / 86)\end{array}$ & Nicaragua \\
\hline Thailand & 0.8098 & & & & & & & \\
Mexico & 0.6523 & 0.7222 & & & & & & \\
Guatemala & 0.6481 & 0.7407 & 0.8245 & & & & & \\
Panama & 0.5467 & 0.6518 & 0.7091 & 0.9417 & & & & \\
Venezuela & 0.5160 & 0.6314 & 0.6703 & 0.7365 & 0.9298 & & & \\
Costa Rica (11/86) & 0.5291 & 0.6340 & 0.7013 & 0.8077 & 0.7753 & 0.8499 & & \\
Costa Rica(12/86) & 0.5245 & 0.6005 & 0.6705 & 0.7572 & 0.7267 & 0.7814 & 0.7798 & 0.7822 \\
Nicaragua & 0.4983 & 0.5955 & 0.6794 & 0.7442 & 0.6767 & 0.7555 & 0.7483 & 0 \\
\hline
\end{tabular}

highlights the distinction between these populations and the others analysed. The populations sampled from Panama and Venezuela exhibit greatest similarity with the Costa Rican (11/86) population and may therefore have originated from this region of Costa Rica. A dendrogram displaying hierarchial associations is given in Fig. 4. The dendrogram is generated by group-average clustering where the similarity between two groups is defined as the average similarity of all points of unit involving a member of each group. The Thailand, Guatemalan and Mexico populations appear to form a distinct group.

The molecular profiles generated for the Guatemalan (59/87) population with SC10-39 combine the amplification products generated from the Thailand populations of G. sepium (SC10-39-G-210 and SC10$39-\mathrm{G}-180$ ). The three phenotypes identified in the Guatemalan sample (Fig. 5a) could be due to allelic amplification products at a single genetic locus.

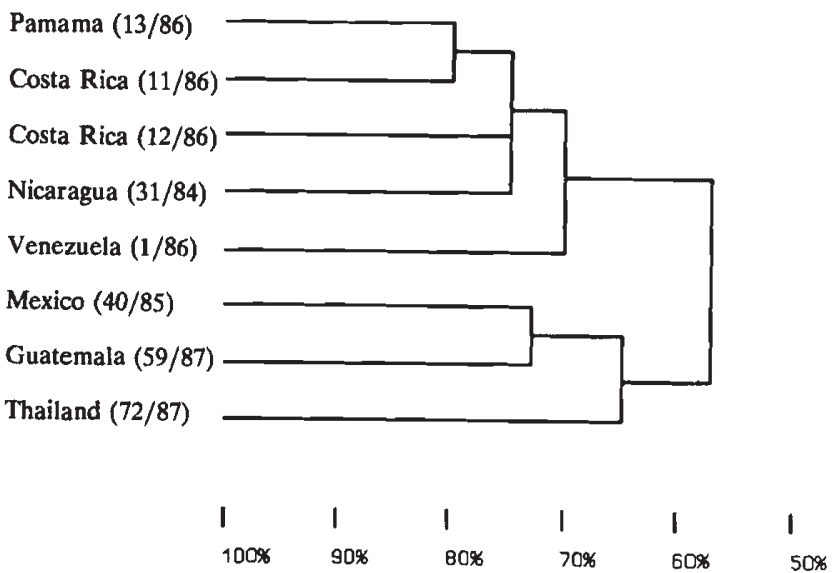

Fig. 4 Dendrogram of $G$, sepium populations generated by group average clustering analysis.
Williams et al. (1990) have demonstrated the RAPD markers tend to be inherited in a dominant/recessive manner. Thus allelism at a single locus would appear to be unlikely. To resolve this issue, the amplification pro-

(a)

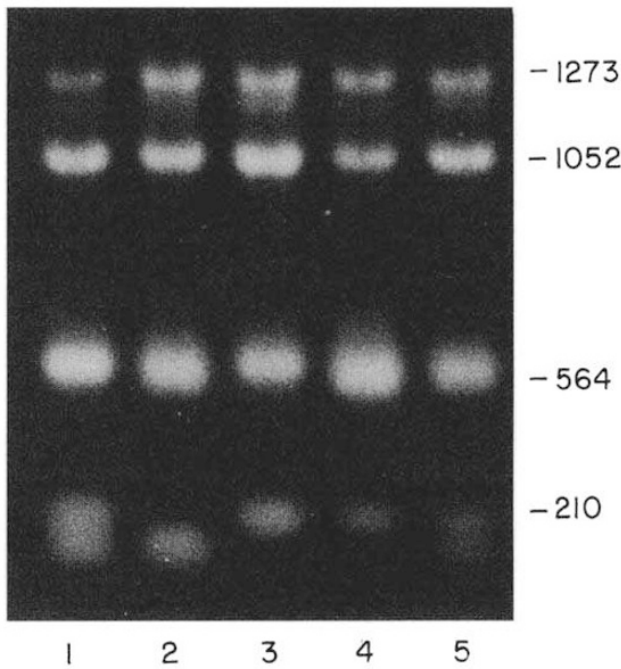

(b)

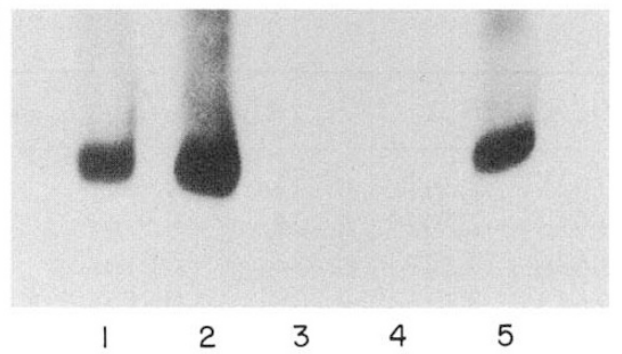

Fig. 5 (a) Amplification products of Gliricidia population from Guatemala with SC10-39. Polymorphic bands SC10 39-G-210 and SC10-39-G-180 are highlighted. (b) SC1039-G-180 was excised from lane 2 in (a) and used to probe a Southern blot of the same amplification products. 
duct $\mathrm{SC} 10-39-\mathrm{G}-180$ was excised labelled with $\left[{ }^{32} \mathrm{P}\right]$ dCTP and used to probe Southern blots of the amplified products. If the amplification products are allelic then one would expect the labelled fragment to hybridize to products from all five genotypes. Figure $5 \mathrm{~b}$ clearly demonstrates that the labelled product only hybridizes to the product with the corresponding size (SC10-39-G-180) and that the products are nonallelic. The amplification products must therefore correspond to two loci.

\section{Discussion and conclusions}

Methods have been established to detect and monitor genetic variability routinely and on a large scale for Gliricidia. The value of RAPD for detecting intrapopulation variation is endorsed by the fact that the provenance ranks of within-provenance variation, given in Table 4, correspond closely with estimates of variation for many quantitative characters assessed in field trials (A. J. Simons, unpublished observations). The polymorphism revealed by amplification of arbitrary primers is extensive and, to our knowledge, this is the first report of the partitioning of genetic variability within and between populations using RAPD markers. Accurate estimates of diversity are a prerequisite for optimizing sampling strategies and for conserving tree genetic resources. The high diversity revealed by RAPD is in agreement with the conclusion that outbreeding woody plants retain considerable variability (Hamrick, 1990). The polymorphic assay procedures used in the present study discriminate well between G. sepium and $G$. maculata and provide molecular support for the conclusion that G. maculata should be considered a distinct taxon.

Most of the diversity was detected between populations. This is contrary to the results accumulated by Hamrick (1990), who indicated that for outbreeding, woody perennial plants, most variation is exhibited within populations. This conclusion, however, is based on isozyme analyses and because these represent only coding regions of the genome, such results may not be directly comparable with the RAPD data for Gliricidia. Primers did differ, however, in their capacity to detect within- and between-population variability (e.g. SC1058 detects most variation within populations). Overall, there appears to be population differentiation, and population-specific amplification products (loci) were identified. This finding lends support to the concept of keeping provenances separate. Therefore, where Gliricidia is to be used as an exotic, it is essential to carry out provenance testing to identify the most appropriate provenance and discourage the multiple introduction of untested seed sources by agencies releasing germplasm of Gliricidia.

Ecological and geographical differentiation are important factors which influence the breeding and sampling strategies of tree crops. It is also essential to consider the relationship between population structure in natural and domesticated populations. Namkoong (1986) has stressed the importance of high levels of genetic variation as a safeguard against co-evolving biotic factors such as pests and diseases. Although Gliricidia is native to Central America, introductions have been made to other tropical regions (Hughes, 1987). In some cases (e.g. in Sri Lanka), introductions were based on single tree progenies and may therefore suffer from inbreeding depression. Multi-purpose trees are generally grown on poor sites with variable climates and differing management practices. It is therefore essential to retain a genetic buffering capacity and identify diverse stocks for distribution. The relatively low levels of polymorphism detected within the Panamanian and Venezuelan populations concur with their putative history of domestication from a restricted genetic base.

At least two of the Gliricidia populations studied, those from Thailand and Venezuela, lie outside the native range. Group-average cluster analysis (Fig. 4) indicates that the Venezuelan population may originate from Costa Rica or Nicaragua. The Thailand population is quite distinct from the other provenances examined but may have originated from Guatemala or Mexico.

Genetic polymorphism detected with RAPD reveals one allele per locus which corresponds to the amplification product visualized (Fig. 1). RAPD are not expected to identify heterozygous loci. Gene flow and mating system are important determinants of the genetic structure of tree populations. Methods of estimating gene flow and mating system are dependent of the ability to detect heterozygotes (Clegg, 1980). In this context, RAPD are limited. However, each primer detected on average seven polymorphic amplification products or loci (Table 3). RAPD may be used to identify heterozygous individuals when a single primer generates at least one complementary polymorphic amplification product from each parent (Baird et al., 1992). Species- and population-specific loci were also identified in this study. The methodology and approach outlined may therefore have a range of applications. In particular, RAPD are a useful predictive tool to identify areas of maximum diversity and may be used to estimate levels of genetic variability in natural populations. We anticipate that RAPD will have a major impact on the management, conservation and improvement of tropical tree crops. 


\section{Acknowledgements}

The authors gratefully acknowledge computing advice from M. S. Phillips. K. J. Chalmers was funded by a grant from the ODA Research Programme in Forestry and Agriculture. W. Powell and R. Waugh are supported by the Scottish Office Agriculture and Fisheries Department.

\section{References}

BAIRD, E., COOPER-BLAND, S., WAUGH, R., DE, MAINE, M. AND POWELL, W. 1992. Molecular characterization of inter- and intra-specific somatic hybrids of potato using randomly amplified polymorphic DNA (RAPD) markers. Mol. Gen. Genet., (in press).

BROWN, A. D. H. 1979. Enzyme polymorphisms in plant populations. Theor. Pop. Biol., 15, 1-42.

ClEGG, M. T. 1980. Measuring plant mating systems. Bioscience, 30, 814-818.

CLEGG, M. T. 1989a. Analyses of molecular diversity within and among plant species. In: Helentjaris, T. and Burr, B. (ed.) Development and Application of Molecular Markers to Problems in Plant Genetics. Current Communications in Molecular Biology, Cold Spring Harbor Laboratory, New York. pp. 51-56.

CLEGG, M. T. 1989b. Molecular diversity in plant populations. In: Brown, A. H. D. (ed.) Population Genetics, Plant Breeding and Genetic Conservation, Sinauer Associates, Sunderland, MA. pp. 98-115.

EDWARDS, K., JOHNSTONE, C. AND THOMPSON, C. 1991. A simple method for the preparation of plant genomic DNA for PCR analysis. Nucl. Acids Res., 19, 1349.

FEINBERG, A. P. AND VogELSTEIN, B. 1984. A technique for radiolabeling DNA restriction endonuclease fragments to high specific activity (Addendum). Anal. Biochem., 137, 266-267.

GOTTLIEB, L. D. 1977. Electrophoretic evidence and plant systematics. Ann. Missouri Bot. Gard., 64, 161-180.

HAMRICK, J. L. 1990. Isozymes and the analysis of genetic structure in plant populations. In: Soltis, E. D. and Soltis, P. S. (eds) Isozymes in Plant Biology. Chapman and Hall, London, pp. 87-105.

HUGHES, C. E. 1987. Biological considerations in designing a seed collection strategy for Gliricidia sepium (JACQ.) WALP. (Leguminosae). Commonwealth For. Rev., 66, 31-48.

INNIS, M. A., GELFOND, D. H., SNINSKY, J. J. AND WHITE, T. J. 1990. PCR protocols. In: A Guide to Methods and Applications. Academic Press, New York.

KING, L. M. AND SCHAAL, B. A. 1989. Ribosomal DNA variation and distribution in Rudbeckia missouriensis. Evolution, 43, 1117-1119.

LOVELESS, M. D. AND HAMRICK, J. L. 1984. Ecological determinants of genetic structure in plant populations. Ann.
Rev. Ecol. Syst., 15, 65-95.

MANIATIS, T., FRITSCH, E. F. AND SAMBROOK, J. 1982. Molecular Cloning: A Laboratory Manual. Cold Spring Harbor Laboratory, New York.

MARTIN, G. B., WLLLIAMS, J. G. K. AND TANKSLEY, S. D. 1991. Rapid identification of markers linked to a Pseudomonas resistance gene in tomato by using random primers and near isogenic lines. Proc. Nat. Acad. Sci., U.S.A., 88, 2336-2340.

MICHELMORE, R. W., PARAN, I. AND KESSELI, R. V. 1992. Identification of markers linked to disease resistance genes by bulked segregant analysis: A rapid method to detect markers in specific genomic regions using segregating populations. Proc. Natl. Acad. Sci., U.S.A., 88, 9828-9832.

NAMKOONG, G. 1986. Genetics and the forests of the future. Unasylva, 152, 2-18.

NEI, M. 1972. Genetic distance between populations. Am. Nat., 106, 283-292.

NEI, M. AND LI, W.-H. 1976. The transit distribution of allele frequencies under mutation pressure. Genet. Res., 28 , 205-214.

NEI, M. AND LI, W.-H. 1979. Mathematical model for studying genetical variation in terms of restriction endonucleases. Proc. Natl. Acad. Sci., U.S.A., 74, 5267-5273.

QUIROS, C. F., HU, J., THIS, P., CHEVRE, A. M. AND DELSENY, M. 1991. Development and chromosomal localization of genomespecific markers by polymerase chain reaction in Brassica. Theor. Appl. Genet., 82, 627-632.

RAFALSKI, J. A., TINGEY, S. V. AND WILliAMS, J. G. K. 1991. RAPD markers - A new technology for genetic mapping and plant breeding. Agbiotech News Inf., 3,645-648.

SAIKI, R. K., GELFOND, D. H., STOFFEL, S., SCHARF, S. J., HIGUCHI, R., HORN, B. T., MULLIS, K. B. AND ERLICH, H. A. 1988. Primer directed enzymatic amplification of DNA with a thermostable DNA polymerase. Science, 239, 487-491.

SIMONS, A. J. 1991. Genetic improvement of non-industrial trees. Agroforest. Syst., 18, 197-212.

SOltis, E. D. AND Soltis, P. S. 1990. Isozymes in Plant Biology. Chapman and Hall, London.

WELSH, J. AND McClELlaND, M. 1990. Fingerprinting genomes using PCR with arbitrary primers. Nucl. Acids Res., 18 , 7213-7218.

WILDE, J., WAUGH, R. AND POWELL, w. 1992. Genetic fingerprinting of Theobroma clones using RAPD markers. Theor. Appl. Genet., 88, 871-877.

WILLIAMS, J. G. K., KUBELIK, A. R., LIVAK, K. J., RAFALSKI, J. A. AND TINGEY, s. v. 1990. DNA polymorphisms amplified by arbitrary primers are useful as genetic markers. Nucl. Acids Res., 18, 6531-6535.

YEH, F. C. H. 1989. Isozyme analysis for revealing population structure for use in breeding strategies. In: Gibson, G. L. Griffin, A. R. and Matheson, A. C. (eds). Breeding Tropical Trees: Population Structure and Genetic Improvement Strategies in Clonal and Seedling Forestry, IVFRO, Pattaya, Thailand. pp. 119-131. 